\title{
Identification of Plum pox virus Pathogenicity Determinants in Herbaceous and Woody Hosts
}

\author{
B. Salvador, M. O. Delgadillo, P. Sáenz, J. A. García, and C. Simón-Mateo \\ Department of Plant Molecular Genetics, Centro Nacional de Biotecnología (CSIC), Campus Universidad Autónoma \\ de Madrid, 28049 Madrid, Spain
}

Submitted 17 July 2007. Accepted 28 August 2007.

\begin{abstract}
Plum pox virus (PPV) is a member of the genus Potyvirus that is able to infect a large variety of plant species, including trees of the genus Prunus, its natural host. When some PPV isolates are propagated for an extended time in herbaceous plants, their ability to infect trees is reduced. The molecular basis of this change in host infectivity is poorly understood. We report the construction of hybrid viruses from cDNA clones of two D-strain isolates of PPV, PPV-D and PPV-R, which differ in their host range. PPVD can infect GF305 peach seedlings efficiently, however, it is unable to infect Nicotiana clevelandii plants. Conversely, PPV-R infects $N$. clevelandii, but not GF305 peach seedlings. The analyses of the hybrid viruses showed that, although determinants of PPV pathogenicity are extensively spread throughout the PPV genome, the $3^{\prime}$ terminal region of the PPV-R genome, including the $3^{\prime}$ noncoding region and the coding regions for the coat protein (CP), NIb, and part of NIa protein, is sufficient to confer infectivity of $N$. clevelandii in a PPV-D background. Our data demonstrate a high concentration of amino acid substitutions in the $\mathrm{CP}$ and a host-specific effect of a deletion at the $\mathbf{N}$ terminus of this protein in PPV pathogenicity in peach and $N$. clevelandii infectivity experiments. These results suggest that relevant host specificity determinants are located in the $\mathrm{N}$-terminal region of the CP. The analyses of the PPV-R and PPV-D chimeras also showed that key host-specific pathogenicity determinants lie in the $5^{\prime}$ terminal third of the PPV genome, a region that spans proteins $\mathbf{P 1}, \mathrm{HCPro}$, and $\mathrm{P3}$. The selection of mutations in only a few specific residues in proteins P1, P3, and $6 \mathrm{~K} 1$ after partial adaptation of a chimeric virus (BD-GFP) to $N$. clevelandii further suggests a relevant role for these proteins in host adaptation.
\end{abstract}

Plum pox virus (PPV) is a member of the large and economically important genus Potyvirus of the family Potyviridae (López-Moya and García 1999). The PPV genome consists of a single-stranded RNA of 9,786 nucleotides. This genomic RNA is translated into a large polyprotein that is proteolitically cleaved by three self-encoded proteinases to produce at least 10 mature protein products (Salvador et al. 2006). In nature, PPV is responsible for a devastating disease that affects several species of the genus Prunus. However, it also

Corresponding authors: J. A. García and C. Simón-Mateo; Telephone: +34 915854535, Fax: +34 915854506; E-mails: jagarcia@cnb.uam.es and csimon@cnb.uam.es

The nucleotide sequence data for pICPPV-Dc is available in the GenBank nucleotide sequence database under the accession number EF569214. can infect a wide range of plant species, including the experimental herbaceous hosts Nicotiana benthamiana, $N$. clevelandii, N. occidentalis, and Chenopodium foetidum (García and Cambra 2007). PPV isolates have been classified into six subgroups or strains: M, D, Rec, C, EA, and W (Candresse and Cambra 2006).

Determinants involved in genome amplification, symptom expression, virus movement between cells and over long distances, as well as in aphid and seed transmission have been identified for several Potyvirus spp. (Revers et al. 1999). However, the ability of PPV to establish local and systemic infections in woody hosts is not fully understood. By constructing genomes that are hybrids from full-length cDNA clones of viruses with different phenotypes, strain- and isolate-specific pathogenicity and host range determinants have been identified. Usually, specific pathogenicity features result form the coordinated action of a number of genetic determinants spread throughout the genome (Chu et al. 1997; Hjulsager et al. 2006; Krause-Sakate et al. 2005). In particular, chimeric viruses constructed from two PPV isolates, PPV-Rankovic (PPV-R) and PPV-PS, has led to the identification of complex determinants of pathogenicity in herbaceous (Sáenz et al. 2000) and woody hosts (Dallot et al. 2001). However, the high sequence divergence between these isolates, which belong to different PPV strains (12.5 and $4.2 \%$ at the nucleotide and amino acid level, respectively), has prevented the precise mapping of the pathogenicity determinants.

In this article, we report the construction of an infectious full-length cDNA clone of a PPV isolate of strain D, named PPV-D. Unlike the previously described cDNA clone of PPVR (Riechmann et al. 1990), also belonging to strain D, the PPV-D clone efficiently initiated infection in GF305 peach seedlings but was unable to infect the herbaceous host $N$. clevelandii. By taking advantage of this difference in host infectivity and the high degree of sequence similarity between PPV-R and PPV-D (99.3 and 99.2\% at the nucleotide and amino acid level, respectively), we engineered recombinant viruses by exchanging fragments of the viral genomes between the infectious cDNA clones to gain insight into the elements of the Potyvirus genome that influence host range selection. Evolution experiments are useful to provide insight into how organism function can improve, offering the opportunity to study beneficial mutations (Elena and Lenski 2003). Thus, to complement the in vitro recombination approach, adaptive evolution of a chimeric virus derived from PPV-D was studied using serial passaging experiments in $N$. clevelandii. An analysis of the mutations that appeared in the adapted variants provides additional information about the viral regions relevant for efficient host infection in an herbaceous plant. 


\section{RESULTS}

A PPV-D cDNA clone causes severe symptoms in GF305 peach seedlings but is not infectious in $N$. clevelandii.

A full-length cDNA of a D-strain PPV isolate (PPV-D) that efficiently infects GF305 peach (Prunus persicae) seedlings was cloned and sequenced (GenBank accession EF569214). Although PPV-D derives from the PPV-Dideron isolate sequenced by Teycheney and associates (1989), we have found differences from the reported sequence of PPV-Dideron (X16415.1) at 46 nucleotide positions, resulting in 17 amino acid changes (Fig. 1A).

The full-length cDNA of the PPV-D isolate was cloned between the $35 \mathrm{~S}$ promoter from Cauliflower mosaic virus and the nopaline synthase termination signal to provide in planta expression of the viral RNA. DNA of the resulting plasmid, pICPPVDc (Dc), was biolistically inoculated onto leaves of GF305 peach seedlings and $N$. clevelandii plants. In peach plants, Dc caused significant leaf distortion, blotches, and vein clearing indistinguishable from those caused by the parental PPV-D iso- late. Consistent with earlier reports defining the host range of PPV-Dideron (Kerlan and Dunez 1979), none of the 25 N. clevelandii plants bombarded with Dc in seven independent experiments displayed any disease symptoms or showed virus accumulation as detected by enzyme-linked immunosorbent assay (ELISA) and Western blot (Fig. 2 and data not shown).

Determinants of PPV-D- and PPV-R-specific host ranges are located throughout the virus genome.

PPV-R is a previously sequenced D-strain isolate (Laín et al. 1989) that has lost the ability to systemically infect Prunus hosts after extended propagation in herbaceous plants (Dallot et al. 2001). Consistent with the host range of PPV-R, infection of $N$. clevelandii, but not of GF305 peach seedlings, was achieved after biolistic inoculation of NK-GFP, a plasmid containing PPV-R sequences and green fluorescent protein (GFP) as a reporter gene (Fernández-Fernández et al. 2001) (Figs. 2 and 3). Sequence analysis showed 68 nucleotide differences between NK-GFP and Dc, resulting in 24 amino acid changes (Fig. 1A). This divergence is slightly larger than the divergence

A

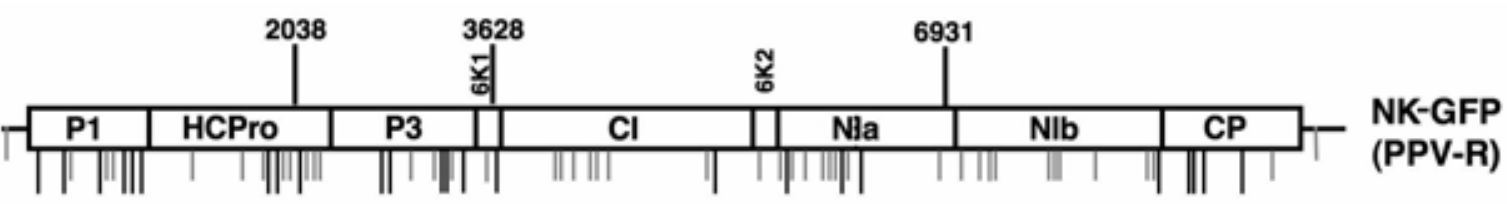

\begin{tabular}{|c|c|c|c|c|c|c|c|}
\hline$\bullet \bullet$ & $\bullet$ & $\bullet \bullet \bullet$ & $\bullet \vdots$ & $\bullet$ & $\bullet$ & $\bullet$ & $\bullet$ \\
\hline
\end{tabular}

Dc (PPV-

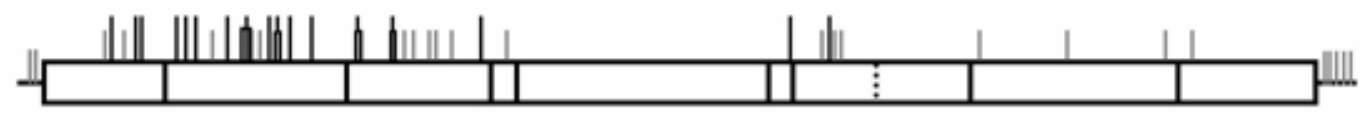

PPVDideron

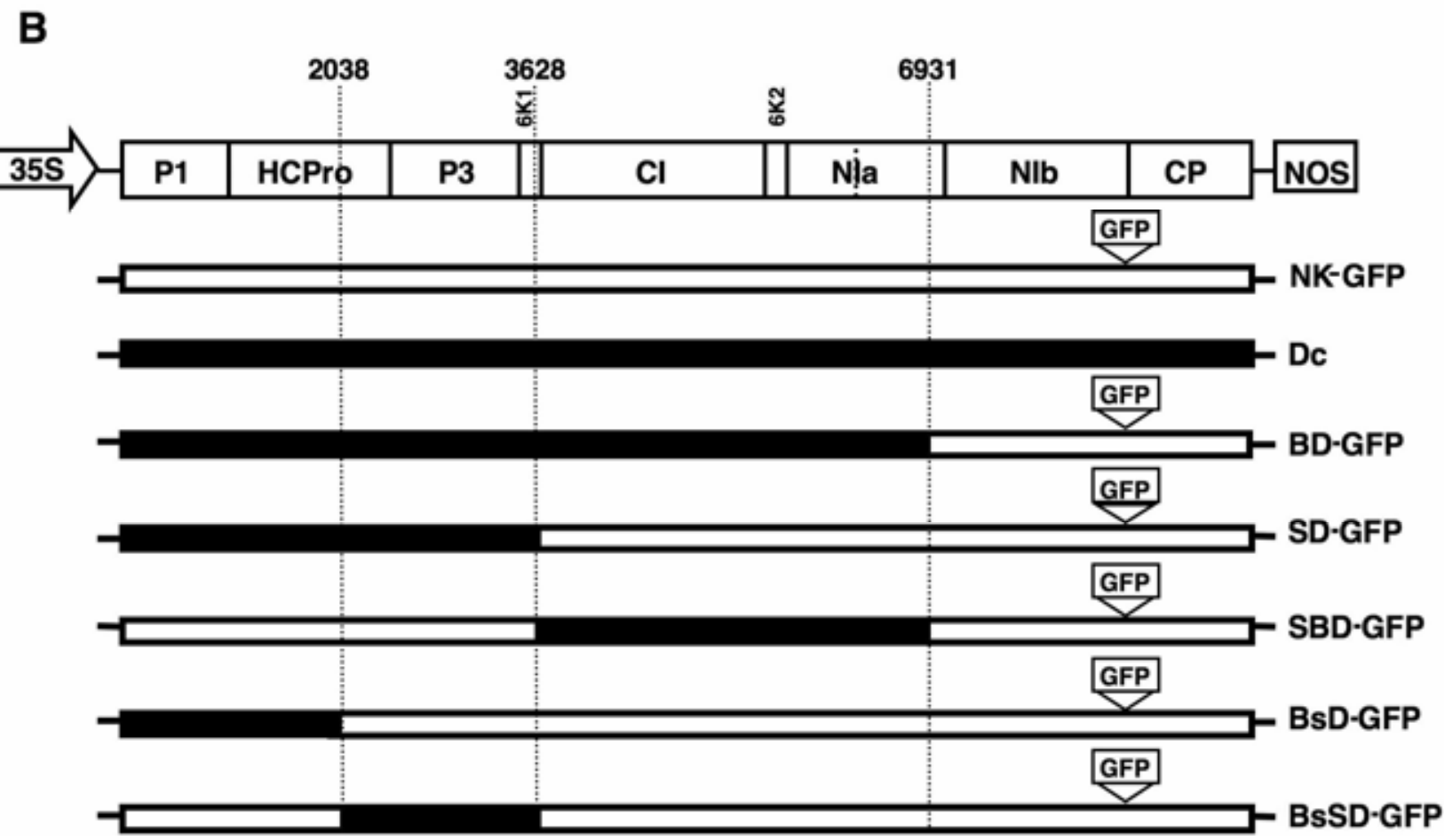

Fig. 1. Comparison of Plum pox virus (PPV)-R, PPV-Dideron, and PPV-D sequences and construction of PPV-D/R hybrids. A, Sequence alignment of PPV$\mathrm{R}$ and PPV-D sequences cloned into pICPPV-NK-GFP (GenBank accession EF569215), and pICPPV-Dc (GenBank accession EF569214), respectively, and the PPV-Dideron sequence (GenBank accession X16415.1). Silent and missense nucleotide changes of PPV-Dideron and PPV-R with respect to PPV-D are represented by short gray and long black vertical lines, respectively. Nucleotide changes shared by both PPV-Dideron and PPV-R sequences are indicated in PPV-D with a black dot (-). B, Schematic representation of PPV cDNA clones NK-GFP (in white), Dc (in black), and the PPV-D/R hybrids constructed from them. The green fluorescent protein (GFP) sequence is represented with a box between NIb and coat protein (CP). In both panels, positions of the restriction sites used for the construction of the hybrids are highlighted with vertical lines, and the PPV-R nucleotide number indicated above. 
between the two related isolates PPV-Dideron and Dc. Interestingly, whereas the differences between Dc and NK-GFP were evenly distributed throughout the genome, Dc and PPVDideron sequences were very similar in the $3^{\prime}$ terminal twothirds of the genome (with only 14 nucleotide changes resulting in two amino acid substitutions between nucleotides 3,631 and 9,786). Most heterogeneities were between nucleotides 413 and 3,630, with 30 nucleotide differences and 15 amino acid changes. This region comprises the C-terminus of $\mathrm{P} 1$, HCPro, P3, and 6K1 viral proteins. Most of the mutations mapped to the HCPro sequence with 14 nucleotide changes and nine amino acid substitutions between nucleotides 1,093 and 2,031 (Fig. 1A).

In order to map the genomic sequences of PPV that determine the host range specificity of the closely related PPV-R and PPV-D isolates, PPV-R and PPV-D chimeras were constructed. Fragments were exchanged between the parental fulllength cDNA clones NK-GFP and Dc (Fig. 1B). All the chimeric viruses contained a GFP sequence between the NIb and coat protein $(\mathrm{CP})$ coding regions to allow the efficiency of viral infection to be monitored. Young plants of $N$. clevelandii and GF305 peach seedlings were biolistically inoculated with various chimeric constructs containing PPV-D-derived nucleotides 1 to $6,931,1$ to 3,628 , and 3,629 to 6,931 , which were correspondingly named BD-GFP, SD-GFP, and SBD-GFP, re- spectively. Each construct was assayed in at least four independent experiments with consistent induction of symptoms and viral accumulation demonstrated for each experiment.

Monitoring of GFP fluorescence, double-antibody sandwich indirect (DASI)-ELISA, and Western blot analyses showed that, in contrast with the Dc clone, all the hybrids assayed in this study were able to initiate a systemic infection in $N$. clevelandii (Fig. 2), indicating that the replacement of the $3^{\prime}$ terminal third of the genome of PPV-D isolate by that of PPV-R was sufficient to confer infectivity of $N$. clevelandii. Notable differences in symptom severity and viral accumulation were observed between the different chimeric viruses. $N$. clevelandii plants infected with BD-GFP were asymptomatic, whereas typical chlorotic mottling was observed in the plants inoculated with SD-GFP or SBD-GFP. Plants infected with SBDGFP displayed severe symptoms similar to those of the plants infected with the parental clone NK-GFP; however, symptoms induced by SD-GFP were much milder (Fig. 2). Differences in virus accumulation were assessed by DASI-ELISA (Fig. 2) and also were confirmed by Western blot (data not shown). The accumulation of progeny virus of BD-GFP and SD-GFP was similar, whereas that of SBD-GFP and NK-GFP was significantly higher (Fig. 2). Strong chlorotic mottling and high viral accumulation detected in the plants inoculated with SBDGFP demonstrated that the PPV-R region comprising nucleo-
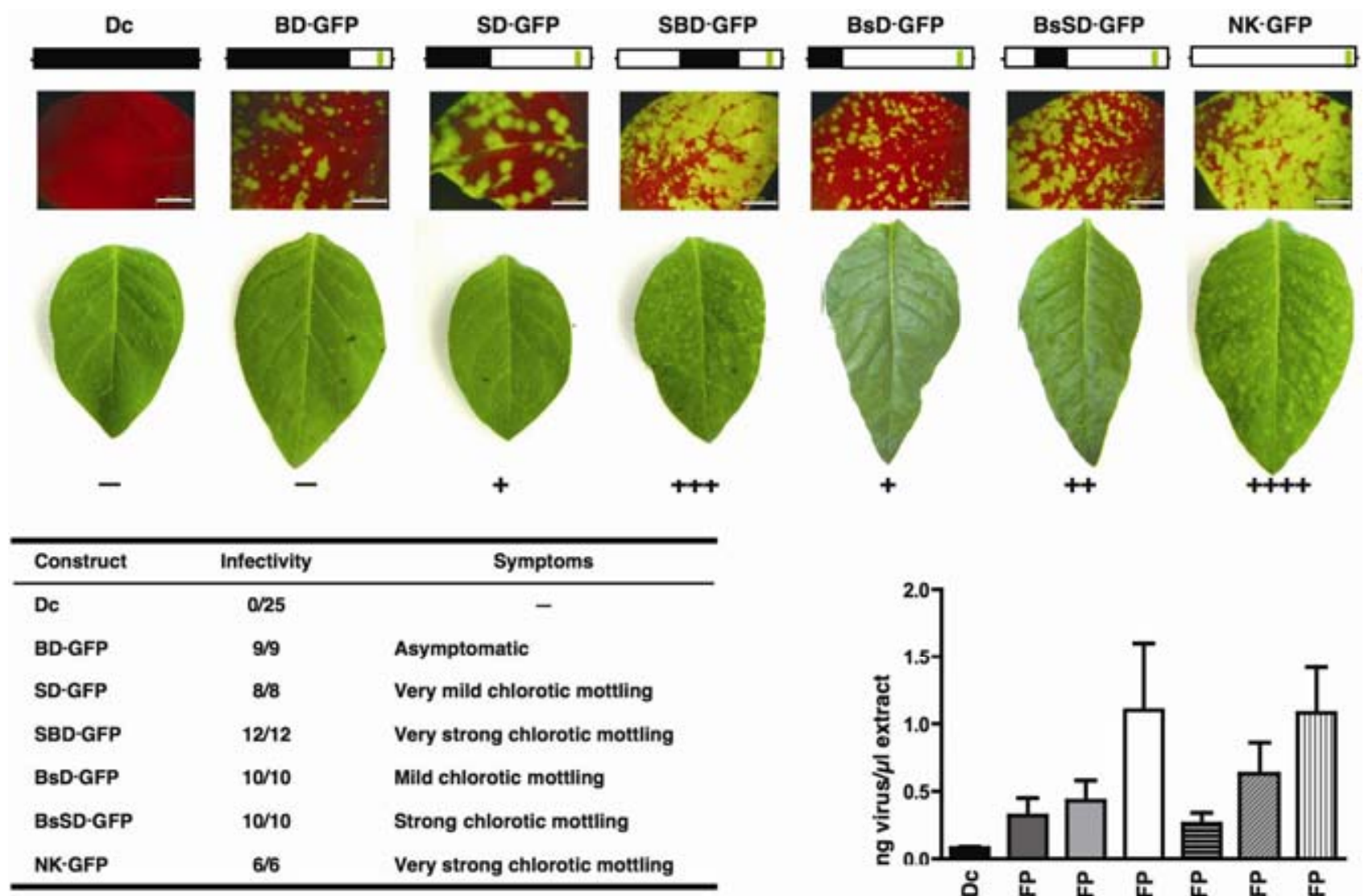

\begin{tabular}{lcl}
\hline Construct & Infectivity & \multicolumn{1}{c}{ Symptoms } \\
\hline Dc & $0 / 25$ & - \\
BD-GFP & $9 / 9$ & Asymptomatic \\
SD-GFP & $8 / 8$ & Very mild chlorotic mottling \\
SBD-GFP & $12 / 12$ & Very strong chlorotic mottling \\
BsD-GFP & $10 / 10$ & Mild chlorotic mottling \\
BsSD-GFP & $10 / 10$ & Strong chlorotic mottling \\
NK-GFP & $6 / 6$ & Very strong chlorotic mottling \\
\hline
\end{tabular}

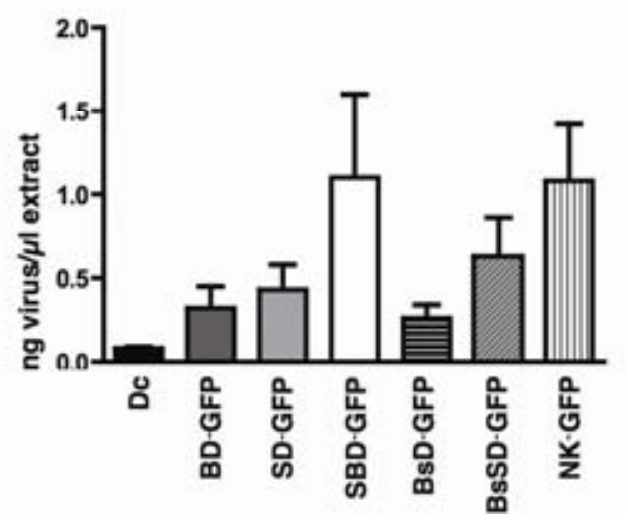

Fig. 2. Phenotypes of the Plum pox virus (PPV)-D/R hybrids expressed in Nicotiana clevelandii. Green fluorescent protein (GFP) expression (upper row), and symptoms (lower row) are shown for young leaves of $N$. clevelandii plants at 21 days postinoculation (dpi). Scale bars correspond to $5 \mathrm{~mm}$. A schematic representation of each virus genome is shown with the corresponding images, and an estimate of the strength of the symptoms is indicated. Regions of the PPV-Dc and PPV-NK-GFP genomes are represented as black and white boxes, respectively. The green box represents the GFP insert. The infectivity of each virus (number of infected plants/number of inoculated plants) and a description of the symptoms induced are presented in the table. The graph shows the virus accumulation in young leaves of infected $N$. clevelandii plants at $21 \mathrm{dpi}$ as determined by double-antibody sandwich indirect enzyme-linked immunosorbent assay. Each bar represents the average value and the standard deviation determined from four different plants. 
tides 1 to 3,628 (which includes sequences coding for P1, HCPro, P3, and part of 6K1) contains important determinants for viral replication and symptom induction in $N$. clevelandii.

In GF305 peach seedlings, both BD-GFP and SD-GFP were able to initiate a symptomatic infection. Infection by BD-GFP caused severe symptoms indistinguishable from those of Dc, whereas symptoms of trees infected with SD-GFP were milder (Fig. 3). SBD-GFP, which was highly infectious in $N$. clevelandii, was unable to induce symptoms in GF305 peach seedlings (Fig. 3). GFP expression also was monitored. Trees infected with BD-GFP had stronger and more widespread GFP expression than SD-GFP-infected plants (Fig. 3). Faint and extremely erratic fluorescent blotches were detected in the few peach trees infected with SBD-GFP (Fig. 3) which never were observed in seedlings inoculated with the parental clone NKGFP. Virus accumulation assessed by ELISA correlated positively with symptom severity and GFP fluorescence intensity. Accumulation differences between Dc- and BD-GFP-infected trees were not statistically significant $(P=0.0537)$; however, SD-GFP accumulation was significantly lower $(P=0.0258)$ (Fig. 3). Virus accumulation in the rare fluorescent blotches of SBD-GFP-infected seedlings was extremely low (Fig. 3).

To further map the genetic determinants conferring the capacity for PPV to infect peach seedlings, two additional chimeras were constructed. The PPV-D region included in the SD chimera was divided into nucleotides 1 to 2,038 (BsD-GFP), and nucleotides 2,039 to 3,628 (BsSD-GFP) (Fig. 1B). N. clevelandii and GF305 peach plants were biolistically inoculated with these two constructs individually, and symptom development and GFP expression were monitored. Infection with BsD-GFP caused mild chlorotic mottling in the upper noninoculated leaves of $N$. clevelandii, whereas plants infected with BsSD-GFP showed strong systemic chlorotic mottling (Fig. 2). Neither symptoms nor GFP were detected in GF305 peach seedlings inoculated with either of these chimeras (Fig. 3). GFP expression was observed in $N$. clevelandii plants inoculated with either construct, and accumulation of both hybrids in $N$. clevelandii correlated with symptomatology, because virus titers of BsSD-GFP were two times higher than those of BsD-GFP (Fig. 2). We conclude that both PPV-D regions included in BsD-GFP and BsSD-GFP are required for peach tree infectivity, and the $5^{\prime}$ third of the PPV-D genome contained in SD-GFP appears to be the minimal region needed to confer infectivity of PPV in peach seedlings.

Altogether, these results using different PPV-R and PPV-D chimeras indicate that the determinants of PPV pathogenicity in $N$. clevelandii and $P$. persicae are not localized in a limited region of the viral genome but, instead, are distributed throughout the PPV genome.
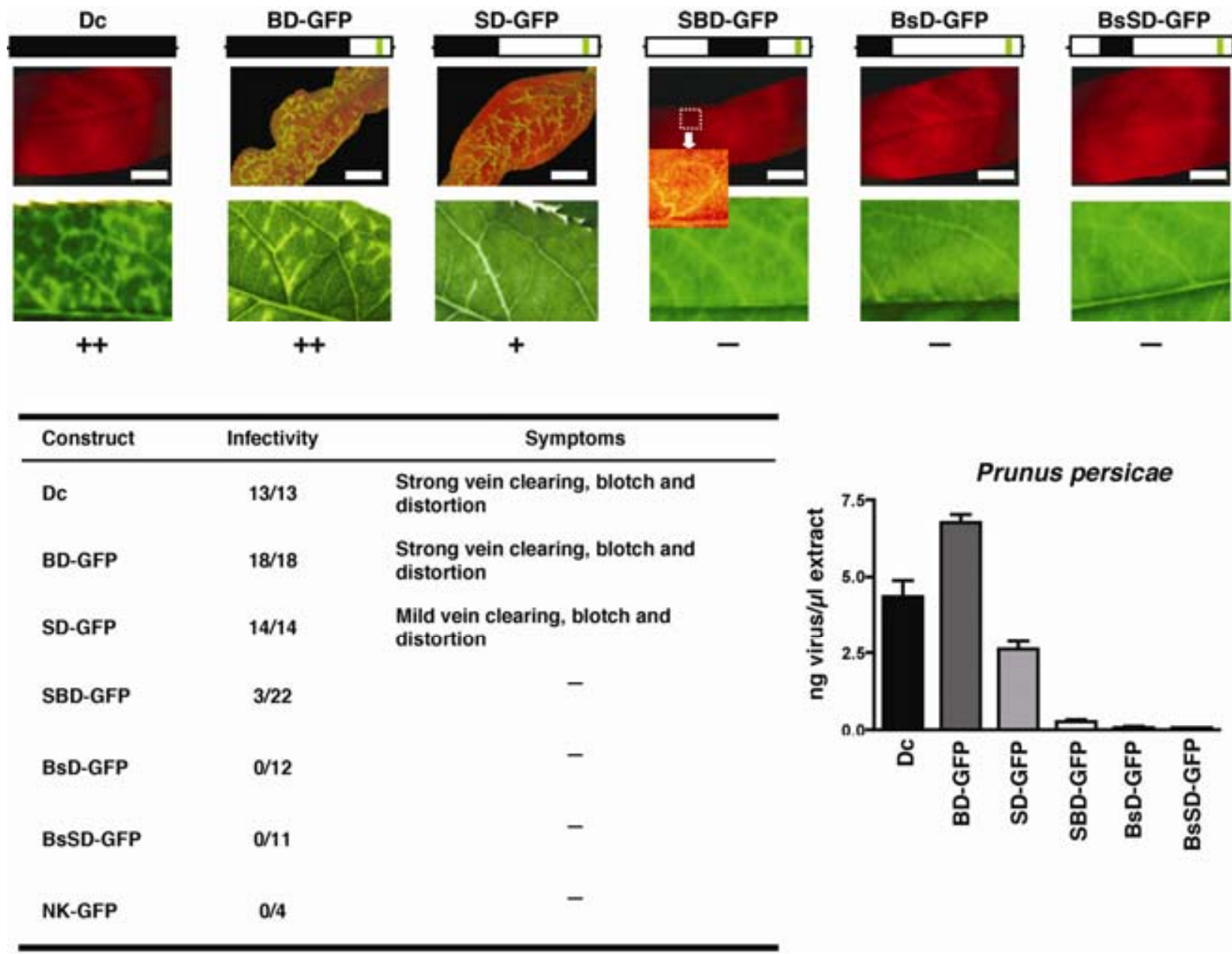

Fig. 3. Phenotypes of the Plum pox virus (PPV)-D/R hybrids in GF305 peach seedlings. Green fluorescent protein (GFP) expression is shown in the upper row and symptoms in the lower row of leaves from GF305 peach seedlings at 35 days postinoculation (dpi). Scale bars correspond to 5 mm. A schematic representation of each virus genome is provided above the corresponding images, and an estimate of the strength of the symptoms is indicated. Regions of PPV-Dc and PPV-NK-GFP genomes are represented as black and white boxes, respectively. The green box represents the GFP insert. The infectivity of each virus (number of infected plants/number of inoculated plants) and a description of the symptoms induced are presented in the table. The graph shows the virus accumulation in young leaves of infected GF305 peach seedlings at 35 dpi as determined by double-antibody sandwich indirect enzyme-linked immunosorbent assay. Each bar represents the average value and the standard deviation determined from five different plants. 
Species-specific competition

of PPV-R and PPV-D chimeras in mixed inoculations.

In order to verify the differences in host-specific fitness between Dc, NK-GFP, and the PPV-R and PPV-D chimeras suggested by the previous single infection experiments, coinoculation of GF305 peach seedlings and $N$. clevelandii plants with pairs of constructs was performed. Based on the viral accumulation data collected for each of the chimeras, the constructs that yielded higher viral accumulation were diluted threefold with respect to the accompanying constructs that produced lower viral levels. Persistence of the competing viruses after 30 days postinoculation (dpi) was detected by performing immunocapture reverse-transcription polymerase chain reaction (IC-RT-PCR) on young infected leaves followed by restriction digestion analysis or sequencing of the amplified products (Table 1).

The PPV-R (NK-GFP) parental virus and the SBD-GFP chimera were the most efficient at infecting $N$. clevelandii. NKGFP and SBD-GFP were the only viruses detected in coinoculation experiments with BD-GFP and SD-GFP, respectively, despite being inoculated at a threefold dilution. In agreement with the similar levels of virus accumulation observed in $N$. clevelandii plants singly infected with SBD-GFP and NK-GFP, no evidence of preference for the parental NKGFP virus over the SBD-GFP chimera was observed. The selection of SBD-GFP in the plants inoculated with this virus combination probably was due to the fact that NK-GFP was threefold diluted in the inoculum. BD-GFP and SD-GFP appeared to have similar fitness in $N$. clevelandii because both viruses were maintained after 30 dpi. SD-GFP was three times less concentrated when coinoculated with BD-GFP; this may suggest a slight preference for SD-GFP multiplication in $N$. clevelandii. In a subsequent experiment where plants were infected with extracts of systemically infected leaves from the initial experiment, both chimeras were still detected (data not shown). Further serial passaging of the chimeras might reveal any minor fitness differences between BD-GFP and SD-GFP in this host, if there are any.

BD-GFP showed higher fitness than SD-GFP when they were coinoculated into GF305 peach plants because only BDGFP was recovered (Table 1). When SD-GFP was coinoculated with SBD-GFP, only SD-GFP was detected in GF305 peach seedlings. This result was consistent with the faint and erratic expression of SBD-GFP observed in the single inoculations experiments in this host. Interestingly, although symptoms and viral accumulation were similar in GF305 peach seedlings individually infected with Dc and BD-GFP (Fig. 3), the Dc parental virus clearly outcompeted the BD-GFP chimera in coinoculated plants (Table 1). These data suggest that the $3^{\prime}$ terminal third of the PPV-D genome is better suited for peach infection than the corresponding genomic region of PPV-R, although the possibility that a detrimental effect of the inserted GFP was responsible for the lower fitness of BD-GFP cannot be ruled out.
Naturally occurring NAT deletion has a host-specific effect on PPV pathogenicity.

Although the $3^{\prime}$ terminal regions of both PPV-R and PPV-D genomes are functional for virus replication and spread in GF305 seedlings (Fig. 3), the higher fitness of Dc in respect to BD-GFP in this host (Table 1) and the inability of Dc to infect $N$. clevelandii (Fig. 2) suggest that this genomic region could contain host-specific pathogenicity determinants. In this respect, the sequence coding for the $\mathrm{N}$-terminus of $\mathrm{CP}$, which is included in the $3^{\prime}$ terminal region of the PPV genome, is one of the most variable regions of the potyviral genome. For this reason, it has been suggested that this part of the CP could be involved in determining host specificity. Consistent with this hypothesis, a deletion of 15 amino acids from this region (Fig. 4A) has been observed after propagation of PPV in herbaceous hosts (López-Moya et al. 1995; Maiss et al. 1989). The deletion is named NAT because the resulting virus is non-aphid transmissible. In order to assess the relevance of the NAT deletion for Prunus spp. and N. clevelandii infections, it was introduced in BD-GFP. The resulting construct, BD-GFP-NAT, was biolistically inoculated into $N$. clevelandii and GF305 peach plants. $N$. clevelandii plants became infected and, as expected, virus derived from BD-GFP-NAT caused an asymptomatic infection similar to BD-GFP infection. Local and systemic GFP foci were similar in size and fluorescence intensity in $N$. clevelandii plants infected with either BD-GFP or BD-GFPNAT (data not shown). All four GF305 peach seedlings inoculated with BD-GFP-NAT were infected, although virus symptoms were delayed in two of the four infected plants. GFP expression also was fainter compared with BD-GFP-infected trees (Fig. 4A). These results suggest that the NAT deletion did not abolish but, rather, impaired PPV infection in peach seedlings. To further confirm this observation, plants of $N$. clevelandii and of GF305 peach were coinoculated with BD-GFP and BD-GFP-NAT by particle bombardment. In N. clevelandii, both viruses still coexisted after 30 dpi (Fig. 4B), suggesting that NAT deletion did not have a drastic effect on viral fitness in this host. Subsequent inoculation of $N$. clevelandii with sap of BD-GFP:BD-GFP-NAT coinfected plants showed that either BD-GFP-NAT is selected, or both viruses coexist after $30 \mathrm{dpi}$ (Fig. 4B). However, the only virus recovered from coinoculated peach seedlings after 30 dpi was BD-GFP, even when it was diluted threefold in the inoculum with respect to BD-GFPNAT (Fig. 4B), confirming that the CP sequences removed by the NAT deletion are relevant for PPV infection of Prunus hosts.

\section{Nucleotide changes associated with adaptation of PPV to $N$. clevelandii.}

To gain insight into viral factors involved in the adaptation of PPV to infection of $N$. clevelandii, serial passaging of BDGFP progeny was performed in this host. In a first series of passaging, no symptoms were detected during the first infec-

Table 1. Virus detection following co-inoculation experiments with Plum pox virus $\mathrm{D}$ and $\mathrm{R}$ hybrids ${ }^{\mathrm{a}}$

\begin{tabular}{|c|c|c|c|c|c|c|c|}
\hline \multirow[b]{3}{*}{ Virus $^{c}$} & \multicolumn{7}{|c|}{ Inoculum 3:1 ${ }^{\mathrm{b}}$} \\
\hline & \multicolumn{4}{|c|}{ Nicotiana clevelandii } & \multicolumn{3}{|c|}{ Peach Prunus persicae GF305 } \\
\hline & BD-GFP:NK-GFP & BD-GFP:SD-GFP & SD-GFP:SBD-GFP & SBD-GFP:NK-GFP & BD-GFP:Dc & SD-GFP:BD-GFP & SBD-GFP:SD-GFP \\
\hline Dc & & $\ldots$ & $\ldots$ & $\ldots$ & $4 / 4$ & $\ldots$ & $\ldots$ \\
\hline BD-GFP & $0 / 3$ & $4 / 4$ & $\ldots$ & $\ldots$ & $0 / 4$ & $4 / 4$ & $\ldots$ \\
\hline SD-GFP & $\ldots$ & $4 / 4$ & $0 / 4$ & $\ldots$ & $\ldots$ & $0 / 4$ & $4 / 4$ \\
\hline SBD-GFP & $\ldots$ & $\ldots$ & $4 / 4$ & $3 / 3$ & $\ldots$ & $\ldots$ & $0 / 4$ \\
\hline NK-GFP & $3 / 3$ & $\ldots$ & $\ldots$ & $0 / 3$ & $\ldots$ & $\ldots$ & $\ldots$ \\
\hline
\end{tabular}

\footnotetext{
${ }^{a}$ Data shown are number of plants infected with the indicated virus/total number of inoculated plants.

${ }^{b}$ DNA ratio for DNA mixtures in the inocula.
}

${ }^{\mathrm{c}}$ Recovered virus after 30 days postinoculation. 
tion rounds. However, by the fifth passage, a chlorotic mottling similar to that of the control NK-GFP-infected plants, but fainter, was observed in the BD-GFP-infected plants, and continued with additional passaging (Fig. 5A, symptoms of a plant infected at passage eight, BD-GFP-A8). GFP fluorescence was stronger and virus accumulation was significantly higher in BD-GFP-A8 plants than in plants directly inoculated with BDGFP progeny virus. However, levels of GFP and virus still were much lower than those of NK-GFP-infected plants (Fig. $5)$. The complete sequence of BD-GFP virus derived from plants infected at passage six (BD-GFP-A6) was determined by direct sequencing of cDNA fragments amplified by IC-RTPCR. BD-GFP-A6 differed from the original BD-GFP cDNA by five nucleotide substitutions, corresponding to three amino acid changes, which were confirmed by sequencing of additional IC-RT-PCR amplification products (Fig. 6). The mutations found in BD-GFP-A6 were absent in plants directly inoculated with BD-GFP, and were found to be maintained after two additional passages (BD-GFP-A8). The changes were located at nucleotide positions 106 of the $5^{\prime}$ noncoding region (NCR), 1,044 (K300Q in P1), 2,772 (D876N in P3), 3,644 (H1166Q in the 6K1-CI protease recognition site), and 9,206 (silent in the CP coding sequence) (Fig. 6B). Interestingly, the three amino acid changes affected residues, which were conserved in Dc and the original PPV-Dideron isolate, which are not able to infect $N$. clevelandii, but were different in the PPV$\mathrm{R}$ (NK-GFP) isolate, which is well adapted to this host. Additionally, the mutation in 6K1 (H1166Q) introduced the same amino acid present in PPV-R.

In order to assess the specificity of the mutations introduced during the adaptation process, a second series of BD-GFP pas- saging in $N$. clevelandii was conducted. There were no noticeable disease symptoms observed after seven passages (Fig. 5A; leaf from an infected plant at passage five, BD-GFP-B5). GFP fluorescence and virus accumulation levels in BD-GFP-B5infected plants were higher than in plants directly inoculated with BD-GFP progeny virus, and were comparable with those of BD-GFP-A8-infected plants (Fig. 5). Sequence analysis of BDGFP-B5 identified two mutations, one at nucleotide 7,014 in the NIaPro coding sequence $(\mathrm{Y} 2290 \mathrm{H})$ and the other at nucleotide 2,773 in the P3 coding sequence. The latter mutation affected the same amino acid that was mutated in BD-GFP-A6, D876 (Fig. 6B). Interestingly, in BD-GFP-B5, D876 was replaced by $\mathrm{Val}$, the same residue present at this position in PPV-R (NKGFP).

\section{DISCUSSION}

Although many plant viruses have restricted host ranges, others are able to infect a large variety of plant species. PPV has the ability to infect both woody and herbaceous hosts (van Oosten 1970, 1975). However, some PPV isolates have lost the ability to infect their natural Prunus hosts after extensive propagation in herbaceous plants. It is the molecular basis of this change in host infectivity that is poorly understood (Dallot et al. 2001).

We constructed an infectious cDNA clone derived from PPV-D (Dc) which, unlike NK-GFP, infects GF305 peach very efficiently but not $N$. clevelandii (Figs. 1A, 2, and 6A). Interestingly, NK-GFP/Dc chimeras were infectious in at least one the two hosts tested, $N$. clevelandii and GF305 peach, but gain of performance in one host was always accompanied by loss of fitness in the other (Figs. 2 and 3; Table 1). BD-GFP chimera

A
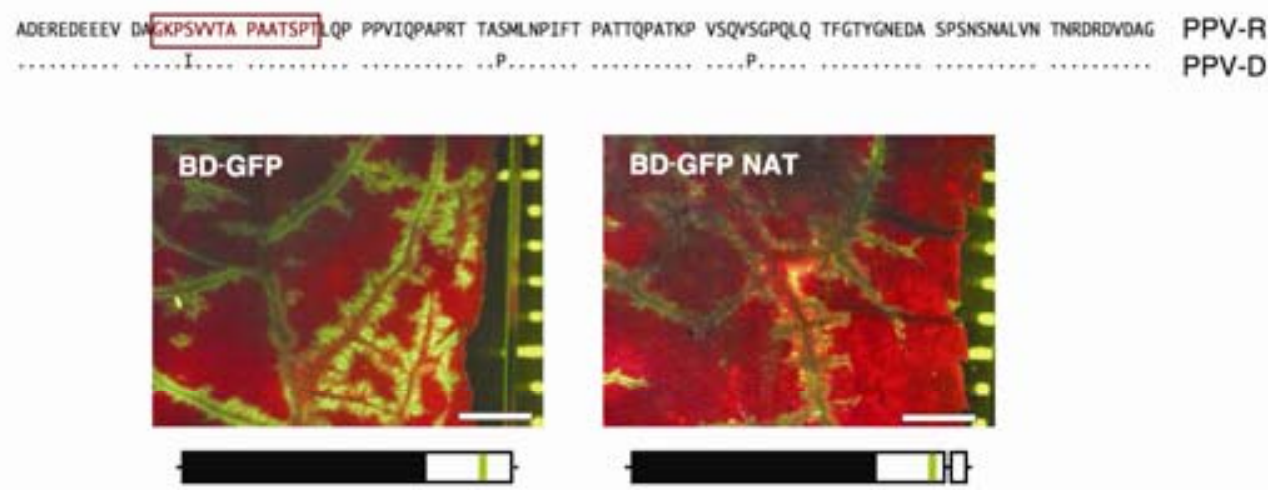

B

BD-GFP:BD-GFP NAT

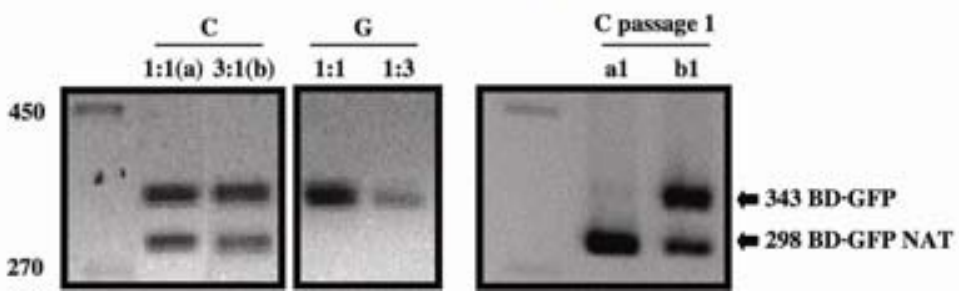

Fig. 4. Effect of NAT deletion on Plum pox virus (PPV) infectivity. A, Alignment of the N-terminal sequence of coat protein (CP) of PPV-R and PPV-D. Amino acids removed by the NAT deletion are shown in red. Images of green fluorescent protein (GFP) expression in leaves of GF305 peach seedlings infected with the indicated viruses are shown. Scale bars correspond to $2 \mathrm{~mm}$. A schematic representation of each virus genome is provided below the corresponding images. Regions of PPV-Dc and PPV-NK-GFP genomes are represented as black and white boxes, respectively. The green box represents the GFP insert. B, Immunocapture reverse-transcription polymerase chain reaction (IC-RT-PCR) products amplified from pools of four Nicotiana clevelandii plants (C) or GF305 plants (G) biolistically inoculated with mixtures of BD-GFP and BD-GFP-NAT DNA, and from pools of four $N$. clevelandii plants inoculated with extracts of pools a and $\mathrm{b}$ of previously co-infected $N$. clevelandii plants (C passage 1 , samples a1 and b1). The DNA ratio of each inoculum is indicated above the lanes. Expected positions of the KpnI-digested IC-RT-PCR products for BD-GFP (343 nucleotides) and BD-GFP-NAT (298 nucleotides) are indicated. Standard size markers are labeled on the left side. 
bearing the coding sequence for 30 amino acids of NIa, the complete NIb and $\mathrm{CP}$, and the $3^{\prime}$ NCR from NK-GFP differed from the parental Dc in that it was able to infect $N$. clevelandii plants, although with low efficiency. Most of the 12 nucleotide differences between Dc and BD-GFP present in the $3^{\prime} \mathrm{NCR}$ and $\mathrm{NIb}$ coding region were silent, except for one conservative amino acid substitution (Figs. 1 and 6A). In contrast, four of the five nucleotide changes in the $\mathrm{CP}$ coding sequence resulted in amino acid substitutions, three of them in the highly variable $\mathrm{N}$-terminal region (Figs. 1 and 6A). Interestingly, one of these changes is in the region where the natural NAT deletion, which has been found to be associated with the propagation of PPV

A
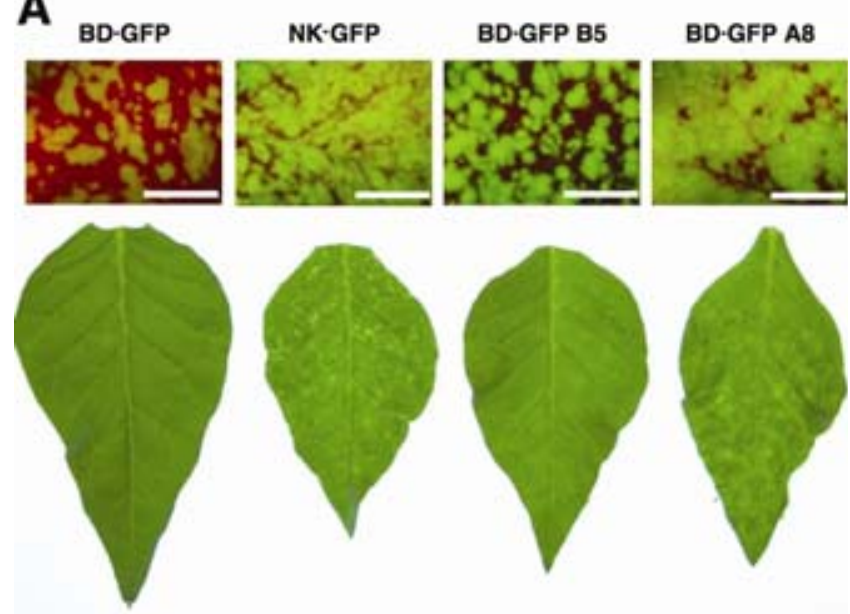

B
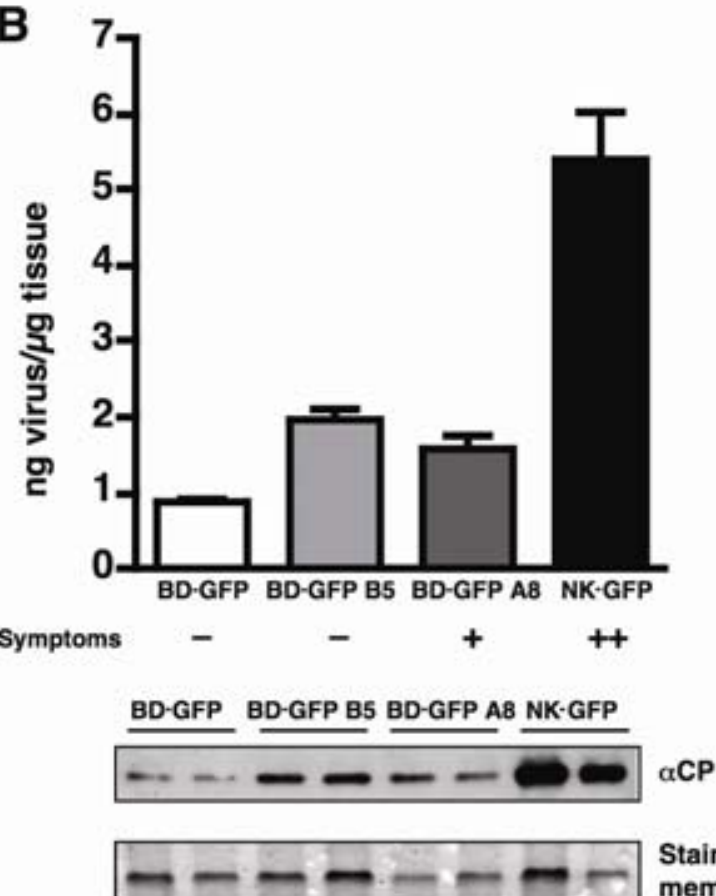

Stained membrane

Fig. 5. Phenotypes of BD-GFP derivatives partially adapted to Nicotiana clevelandii. A, Images of green fluorescent protein (GFP) expression (upper row) and symptoms (lower row) in young leaves of $N$. clevelandii plants at 21 days postinoculation (dpi). Scale bars correspond to $5 \mathrm{~mm}$. B, Accumulation of virus in the young leaves of infected $N$. clevelandii plants at 15 dpi was detected by double-antibody sandwich indirect enzymelinked immunosorbent assay. Each bar represents the average value and the standard deviation from four different plants. Western blot analysis of infected plant extracts is shown below the graph. Each lane corresponds to a sample of young leaves collected 15 dpi from two N. clevelandii plants infected with the virus indicated above each lane. Ponceau staining of the blot is shown at the bottom as a loading control. in herbaceous hosts (López-Moya et al. 1995; Maiss et al. 1989), is located. Moreover, in a mixed infection experiment of $N$. clevelandii, BD-GFP-NAT prevailed over BD-GFP (Fig. 4B). These data might suggest that a host-specific deficiency of plant-virus interactions involving the N-terminus of $\mathrm{CP}$ could be the cause of the inability of Dc to infect $N$. clevelandii. On the other hand, the higher fitness in peach seedlings showed by Dc over BD-GFP and by BD-GFP over BD-GFPNAT in the competition assays (Table 1; Fig. 4) further supports the hypothesis that some host-specific pathogenicity determinants lie in the $\mathrm{N}$-terminus of $\mathrm{CP}$

BD-GFP and SD-GFP differ at 21 nucleotide positions, resulting in one amino acid substitution in each of the $6 \mathrm{~K} 1, \mathrm{CI}$, and NIaPro proteins, and two amino acid substitutions in NIaVPg (Figs. 1 and 6A). These changes do not appear to be important for PPV fitness in N. clevelandii (Fig. 2; Table 1); however, in terms of symptom induction in $N$. clevelandii, weak but appreciable symptoms were produced by SD-GFP, in contrast with the asymptomatic infection of BD-GFP. Amino acid changes at the P3-6K1 cleavage site previously were shown to affect symptom severity with no detectable effects on virus accumulation (Riechmann et al. 1995). Interestingly, in the serial passaging of BD GFP in $N$. clevelandii producing the symptomatic virus BD-GFP-A6, the histidine at position 1,166 of $6 \mathrm{~K} 1$ was mutated to glutamine, the amino acid present at this position in NK-GFP and SD-GFP. In contrast, BD-GFPB5 derived from an independent serial passaging, which did not cause symptoms yet achieved similar virus levels, conserved H1166. These results suggest that the amino acid present at position 1,166 in $6 \mathrm{~K} 1$ could be relevant for symptom induction in $N$. clevelandii, although a $\mathrm{Q}$ at this position is not essential for PPV to induce symptoms in this host because SBD-GFP, which has H1166, caused severe symptoms similar to those of NK-GFP (Fig. 2).

Sequence differences between PPV-R and PPV-D in the 6K1CI-6K2-NIa region appear to be relevant for adaptation of PPV to infect the Prunus host because, although both BD-GFP and SD-GFP were able to infect GF305 peach seedlings, BD-GFP completely out-competed SD-GFP (Table 1). However, our data suggest that main species-specific determinants for Prunus adaptation are located in the $5^{\prime}$ terminal third of the PPV genome ( $5^{\prime} \mathrm{NCR}$ and the coding regions for P1, HCPro, P3, and part of $6 \mathrm{~K} 1$ ) because SBD-GFP showed only very rare and isolated infection foci in GF305 peach seedlings (Fig. 3). This region also contains main species-specific pathogenicity determinants for $N$. clevelandii because a significant increase in virus accumulation was observed in SBD-GFP with respect to BD-GFP (Fig. 2). The 30 nucleotide heterogeneities between Dc and NK-GFP at this region are translated into six, three, and five amino acid changes in P1, HCPro, and P3, respectively (Figs. 1 and 6A). Evidence connecting these proteins with virus pathogenicity has been reported previously. HCPro is a multifunctional protein involved in aphid transmission and in suppression of RNA silencing (Syller 2005), and it also has been shown to contain specific symptom determinants (Gal-On and Raccah 2000) and to be involved in a host-specific defect of PPV for systemic infection in N. tabacum (Sáenz et al. 2002). Together with the N-terminus of $\mathrm{CP}$, potyviral proteins $\mathrm{P} 1$ and $\mathrm{P} 3$ are the most variable, suggesting a role for them in virus-host interactions. In the case of P1, the identification of recombination events affecting its coding sequence appears to be linked to host adaptation (Valli et al. 2007). $\mathrm{P} 1$ is a serine protease that self-cleaves at its C-terminus and acts as an accessory factor for genome amplification (Verchot and Carrington 1995). The role of P1 in Potyvirus infection is still unknown, although P1 has been shown to enhance the silencing suppression activity of HCPro (Kasschau and Carrington 1998; Pruss et al. 1997; Rajamäki et al. 2005; Valli et 
al. 2006). Little is known about the function of the potyviral P3 protein which is required for genome amplification (Klein et al. 1994). The P3 protein is the avirulent factor for some resistance genes (Hajimorad et al. 2006; Jenner et al. 2003; Johansen et al. 2001), a pathogenicity determinant relevant for symptom severity (Sáenz et al. 2000), and a host range determinant in Prunus spp. (Dallot et al. 2001) and other plants (Suehiro et al. 2004; Tan et al. 2005). Interestingly, an RNA element in the P3 coding sequence also has been shown to be important for virus replication and movement (Choi et al. 2005). The fact that neither BsDGFP nor BsSD-GFP were able to infect GF305 peach seedlings (Fig. 3) demonstrates that specific determinants for Prunus infection exist in both halves of the $5^{\prime}$ NCR-P1-HCPro-P3 region, further illustrating the complexity of virus-plant interactions that define the host range of PPV. This feature also was observed in $N$. clevelandii because accumulation of neither BsD-GFP nor BsSD-GFP reached the levels of NK-GFP (Fig. 2). Moreover, the fact that the symptoms of the BsSD-GFPinfected $N$. clevelandii plants were more severe than those of the plants infected with SD-GFP or BsD-GFP highlights the relevance of one or both the P1 or N-terminus of HCPro in symptom induction (Fig. 2).

In support of the influence of P3 in host adaptation, the nonconservative mutation $\mathrm{D} 876 \mathrm{~V}$ in this protein was found to be established in a virus population derived from serial passaging of BD-GFP in N. clevelandii (BD-GFP-B5) (Fig. 6). Interestingly, Val was the amino acid present at this position in the $N$. clevelandii-adapted PPV-R isolate (Fig. 6), and a virus variant with another mutation at this position, D876N, was selected in an independent series of passaging of BD-GFP in $N$. clevelandii (BD-GFP-A6) (Fig. 6). These data provide evidence for the relevance of position 876 in the $\mathrm{P} 3$ protein during adaptation of PPV for $N$. clevelandii infection. A second mutation, $\mathrm{Y} 2290 \mathrm{H}$ in NIaPro, was fixed in BD-GFP-B5; however, due to its location in the region of BD-GFP that derives from the $N$. clevelandii-adapted PPV-R isolate, it is not considered to be very relevant for the adaptation process. D876V and $\mathrm{Y} 2290 \mathrm{H}$ were the only mutations observed in BD-GFP-B5, whereas BD-GFP-A6 had four mutations in addition to D876N (Fig. 6). Two of these mutations (A106G and A9206G) were silent and the affected positions were identical in sequence in NK-GFP and Dc. This suggests that these changes are not important for adaptation, although the A106G mutation is located in a region of the 5' NCR that previously has been shown to affect PPV competitiveness in N. clevelandii (Simón-Buela et al. 1997). In contrast, the other two mutations, K300Q (P1 protein) and H1166Q (6K1 protein), represent nonconservative amino acid substitutions at positions displaying sequence divergence between Dc and NK-GFP. An acidic (Glu) and a basic (Lys) amino acid are present at position 300 of P1 in NK-GFP and Dc, respectively. The selection of this mutation in P1 supports a role for P1 in host adaptation. In agreement with this role, amino acid heterogeneities in P1 affecting virus accumulation in $N$. clevelandii also have been observed in subpopulations of PPV-PS, an isolate belonging to the PPV M strain (B. Salvador, J. A. García, and C. Simón-Mateo, unpublished results). Although virus derived from each series of passaging showed similar accumulation levels, they differed in the ability to pro-

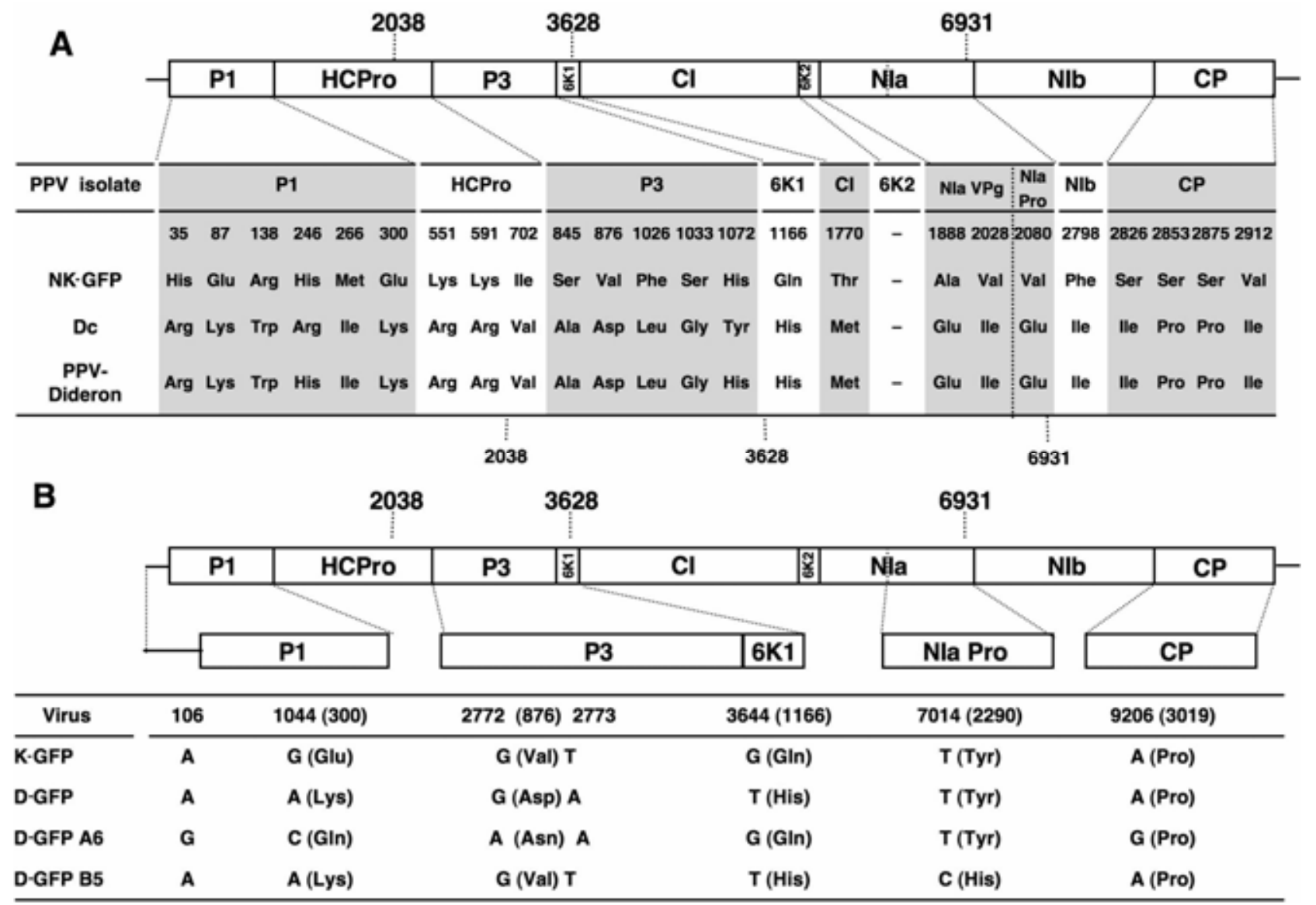

Fig. 6. Amino acid heterogeneities of different Plum pox virus (PPV) variants. A, Amino acid sequences of PPV-Dc, PPV-NK-GFP, and PPV-Dideron at positions where PPV-Dc and PPV-NK-GFP differ. A schematic representation of the PPV genome is depicted above the table. B, Mutations that accumulated in the BDGFP variants obtained by following serial passaging passage in $N$. clevelandii are presented in the table. A schematic representation of the PPV genome is depicted above the table. The regions containing changes are shown above the affected nucleotide positions and the corresponding amino acid residues are indicated in parenthesis. In both panels, vertical dotted lines indicate the nucleotide position of the restriction sites used for the construction of the hybrid viruses. 
duce symptoms in $N$. clevelandii: BD-GFP-B5 generated an asymptomatic infection, whereas plants infected with BDGFP-A8 had mild symptoms (Fig. 5). These data confirm that there is not an absolute correlation between symptom development and virus accumulation, and suggest that other mutations in addition to changes at position 876 (see above for discussion about H1166Q), contribute to enhance virus replication and to facilitate symptom induction.

Levels of viral accumulation of BD-GFP-A8 and BD-GFP-B5 were higher than that of BD-GFP but still lower than that of NKGFP, showing that they adapted only partially to $N$. clevelandii. No further increase in levels of virus accumulation were observed after four additional passages of these viruses in $N$. clevelandii. This suggests that simple and repeated mutations are involved in the first steps of PPV adaptation to $N$. clevelandii, but thorough adaptation requires the coordinated action of a number of mutations that accumulates only after rare and long evolutionary processes.

Our results show that changes that were introduced in the genome of PPV-R during its long-term replication in $N$. clevelandii prevented functional interactions with its natural woody hosts. However, other PPV isolates have been shown to infect both $N$. clevelandii and Prunus spp. (Dallot et al. 2001), demonstrating that the ability of PPV to infect these different hosts is not mutually exclusive. In agreement with this, partially adapted BDGFP-A8 and BD-GFP-B5 still were able to infect GF305 peach seedlings, although competition experiments would be required to ascertain whether adaptation of these viruses to infect $N$. clevelandii corresponds with a loss of fitness in woody plants. Further study of the induced evolution of PPV chimeras could unravel to what extent adaptation to a host affects virus fitness in other hosts, and could provide valuable insight into plant-virus interactions governing virus infection.

\section{MATERIALS AND METHODS}

\section{Viruses and bacteria.}

pICPPV-NK-GFP has been described previously (Fernández-Fernández et al. 2001). PPV-D derives from the PPV-Dideron isolate (Kerlan and Dunez 1979) and was obtained from J. B. Quiot (ENSA-INRA, Bourdeaux, France). The isolate was maintained in GF305 peach trees. Escherichia coli DH5 $\alpha$ was used for cloning of plasmids.

\section{Construction of the infectious PPV-D cDNA clone and sequencing analysis.}

The full-length cDNA clone of PPV-D, named pICPPV-Dc, was constructed by assembling cDNA copies of fragments of the viral genome amplified by IC-RT-PCR. Leaf extracts from infected $P$. persicae cv. GF305 were homogenized in $5 \mathrm{mM}$ sodium phosphate buffer, $\mathrm{pH} 7.5$ (2 ml/g of tissue) and incubated first overnight at $4^{\circ} \mathrm{C}$ and then for $2 \mathrm{~h}$ at $37^{\circ} \mathrm{C}$ in tubes previously coated with anti-PPV immunoglobulin Gs. After two washing steps with phosphate-buffered saline Tween buffer (16 $\mathrm{mM}$ sodium phosphate buffer, $0.1 \mathrm{M} \mathrm{NaCl}$, Tween 20 at 0.5 $\mathrm{g} / \mathrm{liter}, \mathrm{pH}$ 7.2), RT-PCR was performed in the coated tubes using a Titan kit (Roche Molecular Biochemical, Branchburg, NJ, U.S.A.). Primers were designed based on available PPV sequence data and were used to amplify cDNA fragments comprising the complete PPV genome. For sequence analysis, PCR fragments were purified using a Minielute PCR purification kit (Qiagen, Hilden, Germany). GeneScan software was used for analysis of the sequences obtained with the automatic sequencing machine Abi Prism 3700. The full-length clone pICPPV-Dc was prepared by replacing the complete PPV sequence, except for the eight 3' terminal nucleotides, of pICPPV-NK-GFP, a previously described full-length cDNA clone of PPV-R (Fernández-
Fernández et al. 2001), with appropriate restriction fragments of PCR-amplified PPV-D cDNA. The PPV-R (pICPPV-NK-GFP)/ PPV-D (pICPPV-Dc) chimeras shown in Figure 1B were constructed by exchanges of restriction fragments as indicated in the figure. Additional details can be supplied by the authors upon request.

\section{Inoculation and protein analysis.}

$N$. clevelandii plants and GF305 peach seedlings were biolistically inoculated using the Helios Gene Gun System (Bio-Rad, Hercules, CA, U.S.A.). Microcarrier cartridges were prepared with $1.0 \mu \mathrm{m}$ gold particles coated with the different plasmids at a DNA loading ratio of $2 \mu \mathrm{g} / \mathrm{mg}$ of gold and a microcarrier loading quantity of $0.5 \mathrm{mg} / \mathrm{shooting}$, according to the manufacturer's instructions. Helium pressures of 7.5 and 10 bar were used for $N$. clevelandii and peach, respectively. Each cartridge was shot twice onto two leaves of each plant and two cartridges were administered for each plant. For manual inoculation, infected plant leaves were ground with $5 \mathrm{mM}$ sodium phosphate buffer $(\mathrm{pH}$ 7.5) with an ice-cold pestle (1:2 g/ml). Extracts were centrifuged to eliminate tissue fragments in a tabletop centrifuge. For each extract, three plant leaves were dusted with Carborundum and inoculated with a total of $15 \mu \mathrm{l}$ of extract.

Plants were maintained in a greenhouse and virus accumulation was assessed at various days postinoculation by Western blot analysis or DASI-ELISA. For Western blot analysis, proteins were extracted from leaf tissue in disruption buffer (Laemmli 1970). Approximately $2 \mu \mathrm{g}$ of total protein was separated on a $12.5 \%$ sodium dodecyl sulfate polyacrylamide gel electrophoresis gel (Laemmli 1970) and electroblotted onto BioTraceNT Pure Nitrocellulose Blotting Membrane (Pall Corporation, East Hills, NY, U.S.A.). Immunodetection was performed as previously described (García et al. 1992) with anti-CP rabbit serum and anti-rabbit peroxidase conjugate (Jackson ImmunoReseach Laboratories, West Grove, PA, U.S.A.). The peroxidase reaction was developed with an ECL kit (Amersham Pharmacia Biotech, Piscataway, NJ, U.S.A.). For DASI-ELISAs, leaves were collected and ground into 5 $\mathrm{mM}$ sodium phosphate buffer ( $\mathrm{pH} 7.5)$ with an ice-cold pestle $(1: 2 \mathrm{~g} / \mathrm{ml})$. The plant extract was diluted in $50 \mathrm{mM}$ sodium carbonate buffer ( $\mathrm{pH}$ 9.6) and applied to 96-well plates (Maxisorp, Nunc, Roskilde, Denmark). The assay was performed using the REALISA kit (Durviz, Valencia, Spain) according to the manufacturer's instructions. A color reaction developed using $p$-nitrophenil phosphate as a substrate. Optical density was determined at $405 \mathrm{~nm}$. Standard curves were obtained by including in the assay known amounts of purified PPV-R virions diluted in the extract of healthy plants. Statistical two-tailed $t$ tests analysis of the data obtained from the ELISA assay were performed using GraphPad Prism Macintosh version 4.0a by Software MacKiev to determine the significance of the differences in virus accumulation.

In the coinoculation experiments, DNA from each plasmid pair was mixed $1: 3$ to obtain a $2 \mu \mathrm{g} / \mu$ l final concentration of DNA. The DNA mixture was subjected to cartridge preparation and biolistic inoculation methods (discussed above). ICRT-PCR, restriction digestion, and sequence analysis were performed at approximately 30 dpi to determine the viral composition of the population replicating in the young leaves.

\section{Serial passaging.}

For serial passaging of virus, young leaves of $N$. clevelandii plants were biolistically inoculated with pICPPV-5'BD-GFP and collected by 30 dpi. Successive passages in $N$. clevelandii plants were carried out every 30 days by hand inoculation as described above. At each propagation step, leaves used as inoculum were checked for GFP expression. 


\section{Detection of GFP.}

Using a MZ FLIII (Leica Microsystems, Buckinghamshire, U.K.) fluorescence stereomicroscope, plant leaves were examined for GFP expression using excitation and barrier filters of 480/40 $\mathrm{nm}$ and $510 \mathrm{~nm}$, respectively. Images were collected with an OLYMPUS DP 70 digital camera with DP Controller and DP manager software (Olympus Optical Co., Ltd., Tokyo).

\section{ACKNOWLEDGMENTS}

We thank J. Bernard Quiot and L. Quiot (INRA, Montpellier) for kindly providing the PPV-D isolate, and E. Dominguez for technical assistance. This work was supported by grants BIO2004-02687 from Spanish MEC, CPE03-022-C5-3 from INIA, SAL/0185/2006 from Comunidad de Madrid, and QLG2-CT-2002-01673 and SP22-CT-2004 from the European Union. B. Salvador was a recipient of an FPI fellowship from MEC.

\section{LITERATURE CITED}

Candresse, T., and Cambra, M. 2006. Causal agent of sharka disease: Historical perspective and current status of Plum pox virus strains. EPPO Bull. 36:239-246.

Choi, I. R., Horken, K. M., Stenger, D. C., and French, R. 2005. An internal RNA element in the P3 cistron of Wheat streak mosaic virus revealed by synonymous mutations that affect both movement and replication. J. Gen. Virol. 86:2605-2614.

Chu, M. H., López-Moya, J. J., Llave-Correas, C., and Pirone, T. P. 1997. Two separate regions in the genome of the Tobacco etch virus contain determinants of the wilting response of Tabasco pepper. Mol. PlantMicrobe Interact. 10:472-480.

Dallot, S., Quiot-Douine, L., Sáenz, P., Cervera, M. T., García, J. A., and Quiot, J. B. 2001. Identification of Plum pox virus determinants implicated in specific interactions with different Prunus spp. Phytopathology 91:159-164.

Elena, S. F., and Lenski, R. E. 2003. Evolution experiments with microorganisms: The dynamics and genetic bases of adaptation. Nat. Rev. Genet. 4:457-469.

Fernández-Fernández, M. R., Mouriño, M., Rivera, J., Rodríguez, F., PlanaDurán, J., and García, J. A. 2001. Protection of rabbits against rabbit hemorrhagic disease virus by immunization with the VP60 protein expressed in plants with a potyvirus-based vector. Virology 280:283-291.

Gal-On, A., and Raccah, B. 2000. A point mutation in the FRNK motif of the potyvirus helper component-protease gene alters symptom expression in cucurbits and elicits protection against the severe homologous virus. Phytopathology 90:467-473.

García, J. A., and Cambra, M. 2007. Plum pox virus and sharka disease. Plant Vir. 1:69-79.

García, J. A., Martín, M. T., Cervera, M. T., and Riechmann, J. L. 1992. Proteolytic processing of the Plum pox potyvirus polyprotein by the NIa protease at a novel cleavage site. Virology 188:697-703.

Hajimorad, M. R., Eggenberger, A. L., and Hill, J. H. 2006. Strain-specific P3 of Soybean mosaic virus elicits Rsv1-mediated extreme resistance, but absence of P3 elicitor function alone is insufficient for virulence on Rsv1-genotype soybean. Virology 345:156-166.

Hjulsager, C. K., Olsen, B. S., Jensen, D. M., Cordea, M. I., Krath, B. N., Johansen, I. E., and Lund, O. S. 2006. Multiple determinants in the coding region of Pea seed-borne mosaic virus $\mathrm{P} 3$ are involved in virulence against sbm-2 resistance. Virology 355:52-61.

Jenner, C. E., Wang, X. W., Tomimura, K., Ohshima, K., Ponz, F., and Walsh, J. A. 2003. The dual role of the potyvirus P3 protein of Turnip mosaic virus as a symptom and avirulence determinant in brassicas. Mol. Plant-Microbe Interact. 16:777-784.

Johansen, I. E., Lund, O. S., Hjulsager, C. K., and Laursen, J. 2001. Recessive resistance in Pisum sativum and potyvirus pathotype resolved in a gene-for-cistron correspondence between host and virus. J. Virol. 75:6609-6614.

Kasschau, K. D., and Carrington, J. C. 1998. A counterdefensive strategy of plant viruses: Suppression of posttranscriptional gene silencing. Cell 95:461-470.

Kerlan, C., and Dunez, J. 1979. Différenciation biologique et sérologique des souches du virus de la sharka Ann. Phytopathol. 11:241-250.

Klein, P. G., Klein, R. R., Rodríguez-Cerezo, E., Hunt, A., and Shaw, J. G. 1994. Mutational analysis of the Tobacco vein mottling virus genome. Virology 204:759-769.

Krause-Sakate, R., Redondo, E., Richard-Forget, F., Jadao, A. S., Houvenaghel, M. C., German-Retana, S., Pavan, M. A., Candresse, T.,
Zerbini, F. M., and Le Gall, O. 2005. Molecular mapping of the viral determinants of systemic wilting induced by a Lettuce mosaic virus (LMV) isolate in some lettuce cultivars. Virus Res. 109:175-180.

Laemmli, U. K. 1970. Cleavage of structural proteins during the assembly of the head of bacteriophage T4. Nature 227:680-685.

Laín, S., Riechmann, J. L., and García, J. A. 1989. The complete nucleotide sequence of plum pox potyvirus RNA. Virus Res. 13:157-172.

López-Moya, J. J., and García, J. A. 1999. Potyviruses (Potyviridae). Pages 1369-1375 in: Encyclopedia of Virology, Second Edition. R. G. Webster and A. Granoff, eds. Academic Press Ltd., London.

López-Moya, J. J., Canto, T., Díaz-Ruíz, J. R., and López-Abella, D. 1995. Transmission by aphids of a naturally non-transmissible Plum pox virus isolate with the aid of Potato virus $Y$ helper component. J. Gen. Virol. 76:2293-2297.

Maiss, E., Timpe, U., Brisske, A., Jelkmann, W., Casper, R., Himmler, G., Mattanovich, D., and Katinger, H. W. D. 1989. The complete nucleotide sequence of Plum pox virus RNA. J. Gen. Virol. 70:513-524.

Pruss, G., Ge, X., Shi, X. M., Carrington, J. C., and Vance, V. B. 1997. Plant viral synergism: The potyviral genome encodes a broad-range pathogenicity enhancer that transactivates replication of heterologous viruses. Plant Cell 9:859-868.

Rajamäki, M. L., Kelloniemi, J., Alminaite, A., Kekarainen, T., Rabenstein, F., and Valkonen, J. P. 2005. A novel insertion site inside the potyvirus P1 cistron allows expression of heterologous proteins and suggests some P1 functions. Virology 342:88-101.

Revers, F., Le Gall, O., Candresse, T., and Maule, A. J. 1999. New advances in understanding the molecular biology of plant/potyvirus interactions. Mol. Plant-Microbe Interact. 12:367-376.

Riechmann, J. L., Laín, S., and García, J. A. 1989. The genome-linked protein and $5^{\prime}$ end RNA sequence of Plum pox potyvirus. J. Gen. Virol. 70:2785-2789.

Riechmann, J. L., Laín, S., and García, J. A. 1990. Infectious in vitro transcripts from a Plum pox potyvirus cDNA clone. Virology 177:710-716.

Riechmann, J. L., Cervera, M. T., and García, J. A. 1995. Processing of the Plum pox virus polyprotein at the $\mathrm{P} 3-6 \mathrm{~K}_{1}$ junction is not required for virus viability. J. Gen. Virol. 76:951-956.

Sáenz, P., Cervera, M. T., Dallot, S., Quiot, L., Quiot, J. B., Riechmann, J. L., and García, J. A. 2000. Identification of a pathogenicity determinant of Plum pox virus in the sequence encoding the C-terminal region of protein P3+6K 1 . J. Gen. Virol. 81:557-566.

Sáenz, P., Salvador, B., Simón-Mateo, C., Kasschau, K. D., Carrington, J. C., and García, J. A. 2002. Host-specific involvement of the HC protein in the long-distance movement of potyviruses. J. Virol. 76:1922-1931.

Salvador, B., García, J. A., and Simón-Mateo, C. 2006. Causal agent of sharka disease: Plum pox virus genome and function of gene products. EPPO Bull. 36:229-238.

Simón-Buela L., Guo H. S., and García, J. A. 1997. Long sequences in the 5' noncoding region of Plum pox virus are not necessary for viral infectivity but contribute to viral competitiveness and pathogenesis. Virology 233:157-162.

Suehiro, N., Natsuaki, T., Watanabe, T., and Okuda, S. 2004. An important determinant of the ability of Turnip mosaic virus to infect Brassica spp. and/or Raphanus sativus is in its P3 protein. J. Gen. Virol. 85:20872098.

Syller, J. 2005. The roles and mechanisms of helper component proteins encoded by potyviruses and caulimoviruses. Physiol. Mol. Plant Pathol. 67:119-130.

Tan, Z. Y., Gibbs, A. J., Tomitaka, Y., Sanchez, F., Ponz, F., and Ohshima, K. 2005. Mutations in Turnip mosaic virus genomes that have adapted to Raphanus sativus. J. Gen. Virol. 86:501-510.

Teycheney, P. Y., Tavert, G., Delbos, R., Ravelonandro, M., and Dunez, J. 1989. The complete nucleotide sequence of Plum pox virus RNA (strain D). Nucleic Acids Res. 17:10115-10116.

Valli, A., Martín-Hernández, A. M., López-Moya, J. J., and García, J. A. 2006. RNA silencing suppression by a second copy of the P1 serine protease of Cucumber vein yellowing ipomovirus (CVYV), a member of the family Potyviridae that lacks the cysteine protease HCPro. J. Virol. 80:10055-10063.

Valli, A., López-Moya, J. J., and García, J. A. 2007. Recombination and gene duplication in the evolutionary diversification of $\mathrm{P} 1$ proteins in the family Potyviridae. J. Gen. Virol. 88:1016-1028.

van Oosten, H. J. 1970. Herbaceous host plants for the sharka (plum pox) virus. Neth. J. Plant Pathol. 76:253-260.

van Oosten, H. J. 1975. Susceptibility of some woody plant species, mainly Prunus spp., to sharka (plum pox) virus. Neth. J. Plant Pathol. 81:199-203.

Verchot, J., and Carrington, J. C. 1995. Debilitation of plant potyvirus infectivity by $\mathrm{P} 1$ proteinase-inactivating mutations and restoration by second-site modifications. J. Virol. 69:1582-1590. 